\title{
Knowledge, Attitude and Practice of Staff on Segregation of Hospital Waste: A Case Study of a Tertiary Private Hospital in Kenya
}

\author{
Jaccobed Wanjiku Maina \\ Lecturer, Nursing Department \\ Presbyterian University of East Africa
}

Doi: 10.19044/esj.2018.v14n9p401 URL:http://dx.doi.org/10.19044/esj.2018.v14n9p401

\begin{abstract}
This study set to find out the knowledge, attitude and practice of hospital staff in segregation of hospital waste. Specifically, the study sought to analyse how healthcare waste is segregated, what organizational factors affect the practice, knowledge on proper management of biomedical waste and the attitude of workers towards the practice. A sample size of 105 respondents was included in the study from a population of 442 members of staff. Stratified random sampling technique was used. A structured questionnaire was administered to the sample. The Statistical Package for the Social Sciences was used for the purpose of data analysis. Data was analyzed using descriptive statistical techniques. Inferences were drawn using chi-square test of significance. Results revealed that waste segregation was done across all the departments at the hospital except the accounts department. Syringes and needles made up most of the waste segregated from the various departments at the hospital. With the exception of surgical blades and needles which were disposed in yellow sharps containers, all the other healthcare wastes were disposed in any of the bins. Clear instructions and guidelines influenced the practice of waste segregation among staff at the hospital. The study recommended that training on health care waste management should be done on a regular basis. Adequate quantity of the right colour of waste disposal bags should be provided. Policies and guidelines should be introduced in order to guide and direct staff on what the institution expects of them. A waste segregation plan should be introduced.
\end{abstract}

Keywords: Waste segregation, Biomedical Waste, Attitude

\section{Introduction}

Medical waste is infectious and hazardous. It poses serious threats to environmental health and requires specific treatment and management prior to 
its final disposal. Estimates show that some 5.2 million people (including 4 million children) die each year from waste-related diseases globally. The growing number of hospitals, clinics, and diagnostic laboratories across the world has caused a tremendous impact on public health and environment (World Health Organization, 2007). Majority of the waste generated from these facilities contain human body parts, body fluids, organs, tissues and blood along with soiled linens, cotton, bandage and plaster casts from infected and contaminated areas along with used needles, syringes and other sharps. It contains pathogens in mass in their invisible forms (EnviroNews, 2005). World Health Organization (WHO, 2002) estimate that contaminated injections with contaminated syringes caused 21 million Hepatitis B Virus (HBV) infections, one million Hepatitis C Virus (HCV) infections and at least 260,000 HIV infections.

According to World Health Organization, health care workers are the most affected by the biomedical waste. They include doctors, nurses, pharmacist and other nonmedical staff members. This is because they are routinely exposed to biomedical waste and risk from many fatal infections due to indiscriminate management of waste. However, many of the affected health care workers are from third world countries where policies and systems to enforce management of health care wastes are weak. It is approximated that more than five hundred health care workers lose their lives in sub-Saharan Africa yearly due to infection as a result of exposure to biomedical waste (Enviro News, 2005).

Some scholars believe that poor training of medical personnel that emphasizes on curative treatment at the expense of preventive health care system is to blame for the increased problem of management of biomedical waste. Improper handling of solid waste in hospitals has therefore been blamed for increased cases of airborne pathogenic bacteria, which adversely affect the hospital environment and community at large, (Rogers, 2005). A study in a tertiary level hospital in New Delhi, India showed that although doctors, nurses, pharmacist and laboratory technicians had higher education levels, they hardly practiced proper waste management at their work place. The current scenario in the country revealed partial or no segregation of waste at the time of generation, which at times is done by the contractors, or the rag pickers. Proper policies, training gaps and poor attitudes are to blame for the current problem in the BWM worldwide today, (U.S. Environmental Protection Agency, 2009). Failure to segregate health care waste coupled with unsafe disposal (for example, contaminated syringes and needles) poses public health risks. Failure to dispose contaminated needles and syringes in the correct way causes serious threat. Unsafe disposal may lead to dangerous repackaging and recycling and eventually unsafe use as a result of dangerous repackaging and recycling. Contaminated injections equipment may be 
scavenged from waste areas and dumpsites and either be reused or sold again (WHO, 2007).

An assessment carried out by the Ministry of Public Health and Sanitation in Kenya in the year 2009 showed some shortfalls in the management of biomedical waste. For instance, $27 \%$ of health care facilities segregated all waste, $55 \%$ did partial segregation while $18 \%$ did not segregate waste apart from the sharps. Only $30.4 \%$ of health care facilities across the country label waste receptacles. The increased cases of nosocomial infection such as TB, dysentery and other water born diseases in health care facilities has been attributed to indiscriminate management of biomedical waste, (MOH,2007). The fact that more than $60 \%$ of hospitals across the country do not label their waste receptacle is to blame for the current problem in the management of biomedical waste, (WHO, 2007). There was therefore the need to find out why this happens and address the problem. This study set to find out the knowledge, attitude and practice of M.P. Shah Hospital staff in segregation of hospital waste. The research questions were; how is health care waste segregated at the hospital? What organizational factors affect the practice of healthcare waste segregation at hospital? Do hospital staff have knowledge on proper management of health care waste? What is the attitude of hospital staff towards the practice of segregation of health care waste?

\section{Literature Review}

The entire globe is facing the problem of ecological imbalance and environmental pollution. Industrial and other wastes are proving disastrous for animal and floral life on the earth hence the need of a planned waste management. Hospital waste includes hazardous/toxic material which needs careful planning for its safe disposal (Rolando, Loida \& Danilo, 1997) Biomedical waste can be classified according to content, nature and place of generation criteria. These include pathological waste, infectious waste, sharps, pharmaceutical wastes, radioactive waste and chemical wastes. Pathological waste contains pathogens in sufficient concentration or quantity that exposure to it could result in disease. This category includes cultures and stock of infectious agents from laboratory work, waste from surgery and autopsies on patients with infectious diseases. On the other hand pharmaceutical wastes are outdated drugs and other chemicals returned from wards for disposal. Radioactive wastes may be in liquid, solid or gaseous form. It is generated as a result of contamination with radio nucleosides used on body tissues and fluids during in vitro analysis. Finally, Chemical wastes are discarded, solid, liquid, and gaseous chemicals (Pruss, Giroult \& Rushbrook, 1999).

Waste segregation is the systematic separation of solid waste into designated categories. Segregation of waste should be carried out at the source by the producer at the place of generation. The person generating the waste for 
example the nurse or doctor at the bedside, on the ward, casualty or operating theatre should segregate the waste. Waste segregation policy should be applied during collection, transportation, storage, and final disposal. (Sandra, GTZ, 2009). An appropriate way of identifying the waste is by sorting the waste into different colour code. Colour code is easy for identification and thereby easy for safe handling, transportation and waste treatment. There is no specific colour code for medical waste management. The colour code varies from country to country, as it depends upon many factors, such as socioeconomic status, literacy rate, availability of local resources, countries classification of waste etc (Pruss et al., 1999).

A study by Saini, Nagarajan \& Sarma (2005) demonstrated that segregation and separation of plastic waste was done better by the nurses. A significant difference was found between the biomedical waste practices among nurses, technical staff and housekeeping staff. Nurses were found to practice biomedical waste segregation better. Out of $95(19 \%)$ who separated plastic waste, $56(59.8 \%)$ were nurses. The results also showed that $100 \%$ nurses, $70 \%$ housekeeping staff, and only $47 \%$ of the technical staff practiced biomedical waste segregation. Compliance with the standard procedures was observed at Jhansi during the process of segregation, collection, transport, storage, and final disposal of infectious waste. It was also found that the noninfectious waste was collected separately in different containers and treated as general waste. (Patil \& Pokhrel, 2005).

In Chandigarh biomedical waste is disposed of along with municipal waste in the medical establishments both in the rural and urban area and no waste management system exists (Singh \& Arora, 2004). In one of the district in Gujarat, there was no effective waste segregation, collection, transportation and disposal system at any hospital (Saini et al., 2005) .In Karachi, it was observed that $25 \%$ hospitals were segregating sharps, pathological waste, chemical, infectious, pharmaceutical and pressurized containers at source. (Rasheed \& Iqbal, 2005).

Another study carried out in Tanzania employed random sampling design to obtain the LLHFs. These included health centres and special clinics. Most of the surveyed LLHFs in the two municipalities segregated medical waste into infectious and non-infectious waste. In some facilities even though segregation was performed, sharp wastes were later found mixed with general waste during incineration. So in some facilities, segregation was not perfectly performed, despite the availability of specific containers for waste collection. In most of the facilities no proper segregation as general waste and sharps waste were observed mixed in common collection vessels (Manyele \& Lyasenga, 2010).

A study carried out on knowledge, attitude and practices regarding biomedical waste among paramedical workers in India found out significant 
correlation between education, attitude and BWM activities in health care settings. The findings in this study showed that $85 \%$ nurses, $14 \%$ housekeeping staff and $12 \%$ technical staff had knowledge about biomedical waste. The study also showed that while doctors had knowledge of risk of health hazards, the auxiliary staff knowledge was very poor. The nurses were found to have significantly positive attitude compared to the technicians and housekeeping staff. The study found that $98 \%$ of the nurses, $79 \%$ of the house keeping staff, and $59 \%$ of the technical staff had a positive attitude. (Pandit, Mehta, Kartha \& Choudhary, 2005). However, contrary to the above finding, a similar study carried out in Bangladesh showed that awareness and proper practice of BMW was very satisfactory for all health care workers regardless of educational level (Rao, 2008). The study showed that the majority of staff were conscious of the measures for safe collection and final disposal of BMW. This was in contrast to the finding reported by Pandit et al who reported that proper hospital waste management was not being practiced. Similar findings to these were observed by (Rao, 2008): In this study a need to periodically acquaint the participants with the updated BMW management and handling rules was felt.

A research done in Karachi showed that $25 \%$ of the hospitals segregated sharps, pathological waste, infectious, pharmaceutical, chemical, and pasteurized containers at source. Staff had inadequate knowledge about biomedical waste management. There was a positive attitude which was found to improve the current situation in biomedical waste management (Saini et al.,2005). The findings in Gujarat shoed that doctors were aware of risk of health hazards whereas the auxiliary staffs knowledge about it was very poor. From March to September 2009 a hospital based cross sectional study was performed in Karimnagar town, Pradesh, India. Majority of the study subjects (95.8\%) had knowledge about segregation of BMW, of which $48.8 \%$ were nurses. The study showed that doctors knew the risk of health hazards whereas auxiliary staff had very poor knowledge about it (Nagarajan \& Sarma, 2005). The study found that the attitude of the respondents towards separation of infectious and non-infectious waste and proper disposal and implementation of rules was positive. The findings were 496 (99.2\%), 494 (98.9\%) and 492(98.4\%), respectively. The nurses were found to have a better attitude towards separation of waste $236(99.5 \%)$. Compared to the technicians and the house keeping staff the nurses were found to have a significantly positive attitude (Pandit et al., 2005). Another study revealed that $98 \%$ of the nurses and $79 \%$ of the housekeeping staff had a positive attitude while only $59 \%$ of the technical staff had a positive attitude. The nurses were found to have better knowledge and attitude and practiced biomedical waste management better than the technical and housekeeping staff (Nagarajan \& Sarma, 2005). 
Medical waste management in Africa has been found to be similar in South Africa, Swaziland, Mozambique, Tanzania and Kenya. Studies conducted in Tanzania regarding management of hospital waste showed that medical facilities poorly handle waste generated within their premises. These problems streams right from the hospital administration staff to the individual health care providers who seemingly have low attitude towards hospital waste management (Manyele \& Lyasenga, 2010).

In Kenya, a study carried out across the country on the state of biomedical study has revealed that biomedical waste handlers including health care workers have low knowledge on proper biomedical waste management techniques. They therefore risk infections such as HIV and Hepatitis from needle pricks while open burning produces harmful gases resulting in respiratory problems, cancers and reproductive health problems ( $\mathrm{MoH}, 2006)$. The study further revealed that tuberculosis; HIV and Hepatitis are diseases that waste handlers across the country have high risk of being infected with.

Education and understanding of what constitutes hazardous red bag medical waste is the first step in an effective Medical Waste Reduction Plan (MWRP). Medical facilities, such as hospitals and nursing homes can save a lot of money by implementing a comprehensive Medical Waste Reduction Plan and improving their waste segregation and disposal. Proper education and medical facility policy can realistically decrease hazardous waste to a mere $6-10 \%$ of their waste stream. Utilizing the proper, specially designed disposal containers that include the proper signage, bio-hazard label as well as other applicable labelling, provides instructions and on-the-spot education to help reduce solid waste that is casually tossed in by the medical staff out of convenience rather than necessity (West Bengal Health System Development Project (WBHSDP). (2002-2003).1121212

Healthcare waste mismanagement poses considerable risk to the environment and people. All healthcare workers, patients, waste pickers, waste handlers and the general public are exposed to health risks from infectious waste. This includes sharps and other healthcare wastes that may transmit diseases through injuries from contaminated sharps (WHO, 2002). These include amongst others Hepatitis B and C, Human Immune Virus and Acquired Immune Deficiency Syndrome (HIV/AIDS). It is suspected that there has been a number of cases of illness that have occurred both in healthcare establishments and those outside amongst those who either handle such waste or are exposed to it because of carelessness from management. The main groups that are at risk are those handling healthcare waste at the sources and those transporting or disposing of it at the disposal facilities, including scavengers (Pruss et al., 1999). Individuals within healthcare establishments that generate hazardous waste and those exposed to hazardous healthcare waste outside these sources are potentially at risk. 
The most appropriate way of identifying the categories of health care waste according to Pruss et al., (1999) is by sorting the waste into colourcoded plastic bags or containers. A number of practices are recommended in addition to colour coding of waste containers. First, general healthcare waste and domestic refuse is combined for disposal. Secondly, all sharps, whether contaminated or not, should be collected together. Sharps containers should be preferably made of puncture proof material, preferably metal or high density plastic and fitted with covers. They should be impermeable and rigid so that they retain the sharps and any liquids from syringes (WHO, 1998). Thirdly, containers and bags for infectious waste should be marked with the international infectious substance symbol. Fourthly, highly infectious waste should be sterilized immediately if possible by autoclaving. Highly infectious material should be packaged with bags suitable for autoclaving and compatible with the proposed treatment process preferably red bags. Fifthly, expired pharmaceuticals and large quantities of obsolete drugs in wards or departments should be returned to the pharmacy for disposal.

\section{Methodology}

The study design used was a descriptive cross-sectional study to determine the level of knowledge, attitude and practice of health care workers on waste segregation in the hospital. The research was carried out in a tertiary private hospital in Nairobi, Kenya. The study targeted 475 health care workers and non medical staff. Random sampling was employed to select participants from different departments. Each department was represented. Respondents were sampled randomly from ten departments. The researcher went to the respective departments and administered the questionnaire with the help of research assistants. Questionnaires were given to 105 respondents.

Completed questionnaires received from the respondents were stored safely for processing. All raw data were also stored safely by the researcher. Recorded data in the questionnaires were checked for consistency and completeness. Data was analysed using the Statistical Package for the Social Sciences (SPSS). Descriptive statistics such as frequencies and percentages were used and inferential statistics using Chi square.

\section{Findings}

Nurses comprised $43.8 \%$, (42) of the respondents followed by housekeepers $11.5 \%,(11)$ and administrative officers $8.3 \%,(8)$. Doctors were $7.3 \%$ (7), lab technicians $-4.2 \%$ (4) and kitchen staff $-3.1 \%$ (3). Other respondents with various designations were $21.9 \%$ (21). $61.5 \%$ (59) of the respondents had worked at the hospital for 5 or less years, $14.6 \%$ (14) had worked for 6-10 years while 8.4\% (9) and another 9.4\% (9) had worked for between 11-15 years and 20 or more years each, respectively. 5.2\% (5) of the 
respondents had worked for between $16-20$ years. $83.3 \%$ (80) of the respondents segregated waste while $16.7 \%$ (16) did not. $100 \%$ of staff in administration, radiology, laboratory, house-keeping and laundry departments segregated waste. Further, $85.4 \%$ of nursing staff, $80 \%$ of staff in main kitchen and $75 \%$ of doctors practiced waste segregation. Only $50 \%$ of pharmacy staff and $37.5 \%$ of accounts department staff segregated waste in their area of work.

The results showed in Figure 1 reveals that syringes and needles comprised the majority of waste segregated from the various departments at the hospital,with $68.7 \%$ (66) and $66.7 \%$ (64) respectively. Others were blood and body fluids with $63.5 \%$ (61) each. Razor blades followed at $57.3 \%$ (55) and human tissue at $51.0 \%$ (49). Fifty percent $50.0 \%$, (48) of the respondents observed that their department generated chemical wastes while other wastes such as paper were the least generated as indicated by $47.8 \%$ (44) of the respondents.

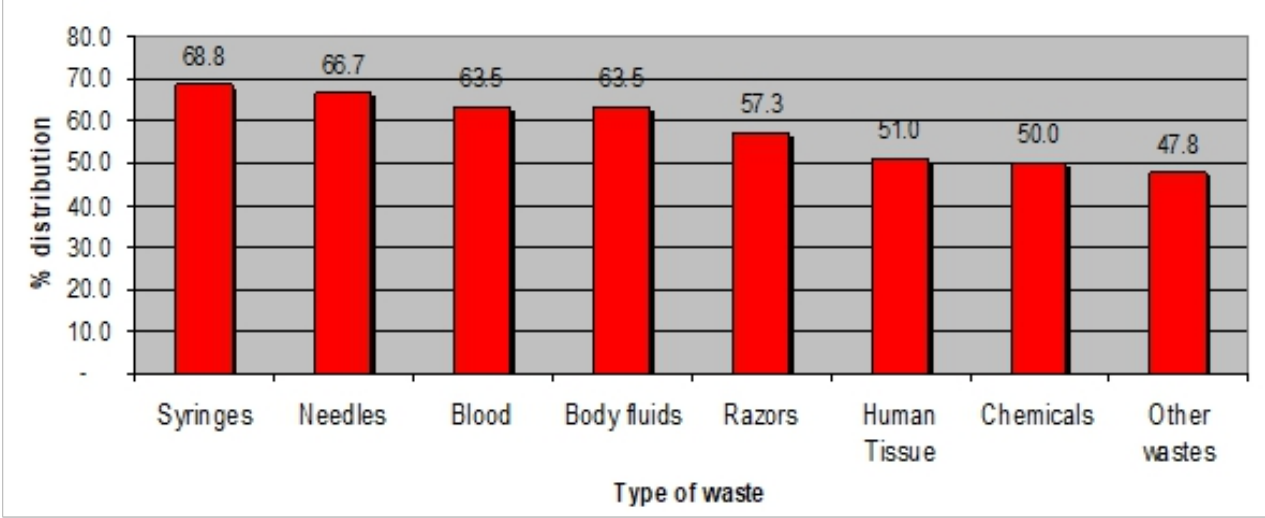

Body fluids were mainly disposed in red bins; razors/blades and needles disposed in yellow (sharps) containers; human tissues disposed mainly in red bins and chemicals also disposed in red bins or the other bins. Other wastes such as paper were disposed mostly in black bins. With the exception of razors/blades which were disposed in yellow bins, all the other healthcare wastes were disposed in any of the bins.

The study sought to determine whether there was a waste documentation system in respondent's area of work. Results showed that $65.6 \%$ (63) of the respondents said no whereas $34.4 \%$ (33) said yes. Further, $55.2 \%$ (53) of the respondents indicated that the essential bags and containers were not enough whereas $44.8 \%$ (43) said they were enough. $53.1 \%$ (51) of the respondents were of the opinion that there were clear instructions or guidelines on waste segregation in their area of work while $46.9 \%$ (45) felt otherwise.

A Chi-squared test was performed to determine if there was any statistically significant difference on the practice of waste segregation due to 
clear instructions or guidelines on waste segregation at the hospital. Crosstabulation results in Table 1 shows that $100 \%$ of the respondents exposed to guidelines on waste segregation adhered to the practice of waste segregation compared to $64 \%$ who were not exposed to the same. There was a statistically significant difference in the practice of waste segregation between respondents who said there was clear instructions or guidelines and those who said there were no instructions $\chi^{2}(1)=21.760, p<.05$. This suggests that the provision of clear instructions or guidelines influences the practice of waste segregation among staff.

Table 1. Clear Instructions and Waste Segregation Cross-tabulation

\begin{tabular}{|c|c|c|c|c|c|}
\hline & & & \multicolumn{2}{|c|}{$\begin{array}{c}\text { Whether Respondent } \\
\text { Segregate Waste }\end{array}$} & \multirow[b]{2}{*}{ Total } \\
\hline & & & Yes & No & \\
\hline \multirow{4}{*}{$\begin{array}{l}\text { Whether there are } \\
\text { clear instructions or } \\
\text { guidelines on waste } \\
\text { segregation in area } \\
\text { of work }\end{array}$} & \multirow[t]{2}{*}{ Yes } & Count & 51 & 0 & 51 \\
\hline & & $\%$ within count & $100.0 \%$ & $.0 \%$ & $100.0 \%$ \\
\hline & \multirow[t]{2}{*}{ No } & Count & 29 & 16 & 45 \\
\hline & & $\%$ within count & $64.4 \%$ & $35.6 \%$ & $100.0 \%$ \\
\hline \multirow{2}{*}{\multicolumn{2}{|c|}{ Total }} & Count & 80 & 16 & 96 \\
\hline & & $\%$ within count & $83.3 \%$ & $16.7 \%$ & $100.0 \%$ \\
\hline
\end{tabular}

Respondents were asked whether they have ever attended any training on health care waste management and segregation. Table 2 shows that only $27.1 \%$ (26) of the respondents had undergone training in healthcare waste management while $72.9 \%$ had not. A Chi-squared test was run to establish if there was any statistically significant impact of staff training on the practice of waste segregation. Results revealed that $100 \%$ of the respondents who undertook training in healthcare waste management practiced waste segregation compared to $77.1 \%$ of the staff who were not yet trained. The chisquare results showed that the relationship between training and practice of waste segregation was statistically significant $\chi^{2}(1)=7.131, p<.05$. This suggests that the training of staff in healthcare waste management was effective in influencing the practice of waste segregation at the hospital.

Table 2. Training and Waste Segregation Cross Tabulation

\begin{tabular}{|c|c|c|c|c|c|}
\hline & & & \multicolumn{2}{|c|}{$\begin{array}{c}\text { Whether Respondent } \\
\text { Segregate Waste }\end{array}$} & \multirow[b]{2}{*}{ Total } \\
\hline & & & Yes & No & \\
\hline \multirow{2}{*}{$\begin{array}{l}\text { Ever attended any } \\
\text { training on Health } \\
\text { Care Waste } \\
\text { Management and } \\
\text { segregation } \\
\end{array}$} & Yes & $\begin{array}{r}\text { Count } \\
\% \text { with count }\end{array}$ & $100.0 \%$ & $.0 \%$ & $100.0 \%$ \\
\hline & No & $\begin{array}{c}\text { Count } \\
\% \text { within count }\end{array}$ & $77.1 \%$ & $22.9 \%$ & $100.0 \%$ \\
\hline & Total & $\begin{array}{c}\text { Count } \\
\% \text { within count }\end{array}$ & $83.3 \%$ & $16.7 \%$ & $\begin{array}{r}96 \\
100.0 \% \\
\end{array}$ \\
\hline
\end{tabular}


It was found that $36.5 \%$ (35) of the respondents were aware of a document outlining the hospital waste management policy, whereas $63.5 \%$ (61) were not. The cross-tabulation table (Table 4.20) below compares the distribution of respondents who observed waste documentation in their area of work with the practice of waste segregation. The table shows that $93 \%$ of the respondents whose department documented waste practiced waste segregation compared to $76.2 \%$ whose area of work did not document waste. There was a statistically significant difference in the effect of documentation on the practice of waste segregation by staff $\chi^{2}(1)=6.732, p<.05$. This suggests that the waste documentation influenced the practice of waste segregation at the hospital.

Table 3. Waste Documentation and Waste Segregate Practice Cross-Tabulation

\begin{tabular}{|c|c|c|c|c|c|}
\hline & & & \multicolumn{2}{|c|}{$\begin{array}{c}\text { Whether Respondent } \\
\text { Segregate Waste in } \\
\text { Area of Work }\end{array}$} & \multirow[b]{2}{*}{ Total } \\
\hline & & & Yes & No & \\
\hline \multirow{2}{*}{$\begin{array}{l}\text { Whether there is } \\
\text { waste documentation } \\
\text { in area of work }\end{array}$} & Yes & $\begin{array}{c}\text { Count } \\
\% \text { within count }\end{array}$ & $\begin{array}{r}32 \\
97.0 \% \\
\end{array}$ & $\begin{array}{r}1 \\
3.0 \% \\
\end{array}$ & $\begin{array}{r}33 \\
100.0 \% \\
\end{array}$ \\
\hline & No & $\begin{array}{c}\text { Count } \\
\% \text { within count }\end{array}$ & $\begin{array}{r}48 \\
76.2 \%\end{array}$ & $\begin{array}{r}15 \\
23.8 \% \\
\end{array}$ & $\begin{array}{r}63 \\
100.0 \% \\
\end{array}$ \\
\hline \multicolumn{2}{|c|}{ Total } & $\begin{array}{c}\text { Count } \\
\% \text { within count }\end{array}$ & $\begin{array}{r}80 \\
83.3 \%\end{array}$ & $\begin{array}{r}16 \\
16.7 \%\end{array}$ & $\begin{array}{c}96 \\
100.0 \%\end{array}$ \\
\hline
\end{tabular}

Further findings indicated that $74.0 \%$ (71) of the respondents defined waste segregation as: the separation, classification, sorting or categorization of waste before disposal. However, some 26\% (25) of the respondents thought of it as a way of collecting or disposing of waste. Therefore, majority of the respondents were knowledgeable concerning the concept of waste segregation. It was also established that $100 \%$ of the respondents in both administration and radiology departments correctly defined waste segregation as the separation, classification, sorting or categorization of waste. The table also shows that $81.3 \%$ of the nurses, $75 \%$ of the doctors and $71 \%$ of the laboratory staff also correctly defined waste segregation. Other departments such as laundry, housekeeping and main kitchen were represented by $66.7 \%$, $66.7 \%$ and $60 \%$ of the respondents, respectively. The accounts and the pharmacy departments scored the lowest in terms of definition as indicated by $50 \%$ and $25 \%$ of the respondents, respectively.

Respondents offered suggestions on what they would do to improve the practice in the institution given an opportunity. These are summarized in the figure below. The figure shows that emphasis was put on training (46.1\%), followed by provision of adequate waste bags (13.2\%) and general awareness on the importance of segregation (11.8\%). Some $10.5 \%$ of the respondents also suggested the development and communication of waste segregation 
policy whereas others $(9.2 \%)$ considered more supervision, clear labelling $(6.6 \%)$ and timely disposal $(2.6 \%)$.

The researcher analyzed the attitudes of staff in terms of the myths and misconceptions, their view of impact of waste segregation on health and sources of discouragement towards the practice.

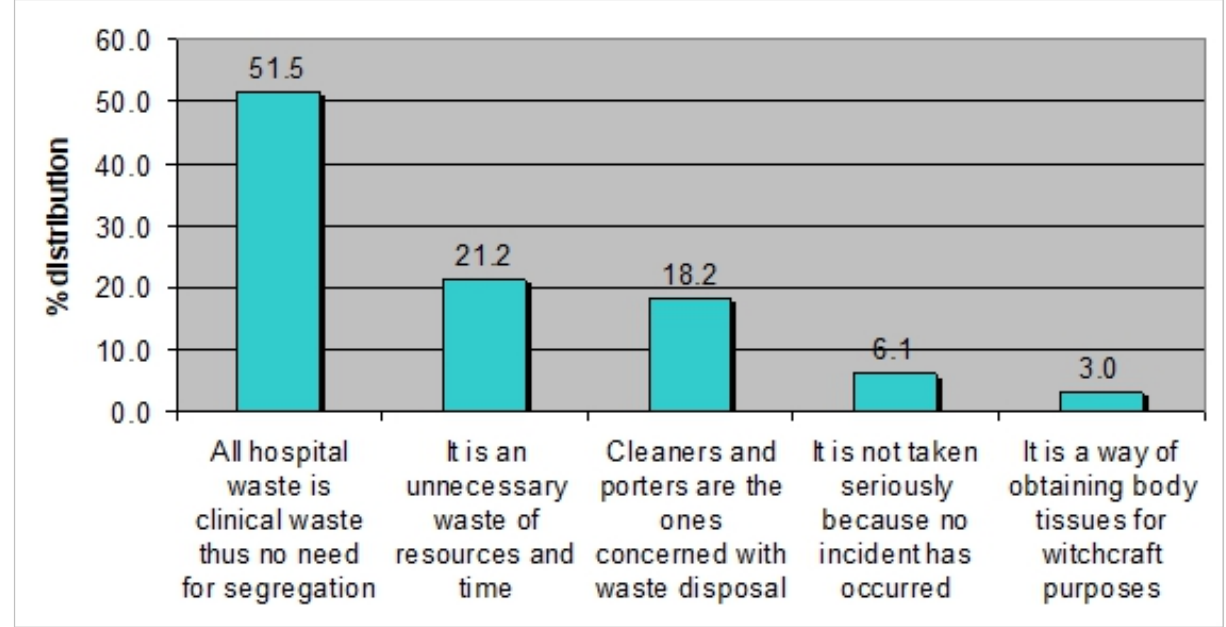

Figure 2. Common Myths and Misconceptions

The study sought to establish from the respondents some of the myths or misconceptions that they know or have heard of on waste segregation in their respective areas of work. Figure 2 above provides a summary of the common misconceptions. The most head of myth or misconception according to $51.5 \%$ of the respondents was that all hospital waste is clinical waste thus there is no need for segregation. In addition, $21.2 \%$ of the respondents said that it was an unnecessary waste of resources and time. Other respondents $(18.2 \%)$ felt that waste segregation is the responsibility of nurses, cleaners and porters. Further, $6.1 \%$ of the respondents observed that it not taken seriously because no incident has occurred while others $(3.0 \%)$ mentioned that it is a way of obtaining body tissues for witchcraft purposes. In terms of attitudes, it was found that $87.5 \%(84)$ and $10.4 \%$ (10) of the respondents strongly agreed and agreed, respectively, that poor waste segregation can create health hazards in the community. However, some $2.0 \%$ (2) of the respondents were not sure whereas no respondent disagreed.

\section{Discussions:}

The study established that syringes and needles comprised the majority of waste segregated in the various departments at the hospital. Others were blood and body fluids, surgical blades, chemicals and human tissue. This agrees with EnviroNews (2005 ) which indicated that majority of the waste generated from these facilities contains human body parts, organs, tissues, 
blood and body fluids along with soiled linens, cotton, bandage and plaster casts from infected and contaminated areas along with used needles, syringes and other sharps. Staff at the hospital are therefore exposed to contaminated syringes and needles which according to WHO (2002) caused 21 Million Hepatitis B Virus (HBV) infections, equivalent to $32 \%$ of all new infections.

The findings however showed that $83.3 \%$ of the respondents segregated waste in their area of work. In terms of departments that handle hazardous waste, $100 \%$ of staff in radiology, laboratory, and house-keeping segregated waste. The results also showed that $85.4 \%$ of nursing staff, and $75 \%$ of Doctors practiced waste segregation. Only $50 \%$ of pharmacy staff segregated waste in their area of work. These results imply that the number of nurses who practiced waste segregation was lower than that of house-keeping and some technical staff at the hospital. This is inconsistent with a previous study by Saini et al., (2005) which established that the nurses practiced biomedical waste segregation better than the technical and housekeeping staff. A possible explanation for this disparity is because of more housekeeping staff (44.4\%) and technical staffs such as radiologists (66.7\%) have undertaken training on healthcare waste management and segregation compared to nursing staff $(29.2 \%)$.

The findings showed that the colour codes used at the hospital were red, black, blue and yellow. This is consistent with Pruss et al., (1999) who argued that an appropriate way of identifying the waste is by sorting the waste into different colour code. This is because colour code is easy for identification and thereby easy for safe handling, transportation and waste treatment. In this study, body fluids were mainly disposed in red bins; blades and needles disposed in yellow (sharps) containers; human tissues disposed mainly in red bins and chemicals also disposed in red bins or the other bins. Other wastes such as paper were disposed mostly in black bins. However, with the exception of needles and blades which are disposed in yellow sharps containers, other wastes were disposed in any of the bins. This latter practice is potentially dangerous as WHO (2006) noted that, while only 15\% of hospital waste is hazardous, when hazardous waste is not segregated at the source of generation and mixed with nonhazardous waste, then $100 \%$ waste becomes hazardous.

The study established that just over half of the respondents were of the opinion that there were clear instructions or guidelines on waste segregation in their area of work. The results showed that all the respondents exposed to guidelines on waste segregation adhered to the practice of waste segregation compared those who were not exposed. Further, a statistically significant difference was established in the practice of waste segregation between respondents who said there was clear instruction or guidelines and those who said there were no instructions, suggesting that the provision of clear 
instructions or guidelines influences the practice of waste segregation among staff.

The study revealed that only $27.1 \%$ of the respondents had undergone training in healthcare waste management. Most of the staff who had received training came from radiology, pharmacy, laundry, housekeeping and nursing departments while accounts, administration, main kitchen and doctors have not. Further, training was mostly done annually. A Chi-squared test showed that $100 \%$ of the respondents who undertook training in healthcare waste management practiced waste segregation compared to $77.1 \%$ of the staff who were not yet trained and the correlation between training and practice of waste segregation was statistically significant, suggesting that the training of staff in healthcare waste management was effective in influencing the practice of waste segregation at the hospital. These findings disagrees with Rogers (2005) who argued that poor training of medical personnel is to blame for the increased problem of management of biomedical waste. In the case of the tertiary hospital, it is not about poor training, but rather, that not all employees have undergone the training.

The study also showed that majority of the respondents was not aware of a document outlining the hospital waste management policy. This agrees with EnviroNews (2005) which suggested that in developing countries, policies and systems to enforce management of health care wastes are still weak. However, there was a statistically significant difference in the effect of documentation on the practice of waste segregation by staff, which implies that waste documentation influenced the practice of waste segregation at the hospital.

The findings showed that majority of the respondent correctly defined waste segregation as the separation, classification, sorting or categorization of waste before disposal. This suggests that they were knowledgeable concerning the concept of waste segregation. The results agree with a similar study carried out in Bangladesh which showed that awareness of biomedical waste was very satisfactory for all health care workers regardless of educational level (Rao, 2008).

In terms of knowledge, the findings revealed that $100 \%$ of the respondents in both administration and radiology departments correctly defined waste segregation as the separation, classification, sorting or categorization of waste. In addition, $81.3 \%$ of the nurses, $75 \%$ of the doctors and $71 \%$ of the laboratory staff also correctly defined waste segregation. Other departments such as laundry, housekeeping and main kitchen were represented by $66.7 \%, 66.7 \%$ and $60 \%$ of the respondents, respectively. The accounts and the pharmacy departments scored the lowest in terms of definition as indicated by $50 \%$ and $25 \%$ of the respondents, respectively. These findings agree with 
the study by Pandit and Mehta (2005) which showed that $85 \%$ nurses, $14 \%$ housekeeping and $12 \%$ technical staff had knowledge about biomedical waste.

The findings showed that respondents put emphasis on training, provision of adequate waste bags and general awareness on the importance of segregation as strategies to improve the practice of waste segregation at the hospital. This agrees with previous literature which suggests that education and understanding of what constitutes hazardous medical waste is the first step in an effective medical waste reduction plan. In this study, majority of the respondents had attained post-secondary (tertiary) education and $26.0 \%$ were university graduates. The scholars rightly argued that medical facilities, such as hospitals can save a lot of money by implementing a comprehensive medical waste reduction plan and improving their waste segregation and disposal.

The findings indicated that the most heard of myth or misconception according to majority of the respondents was that all hospital waste is clinical waste thus there is no need for segregation. Consequently, most of the respondents said that it was an unnecessary waste of resources and time. Other respondents felt that waste segregation is the responsibility of nurses, cleaners and porters. It was particularly interesting to note that none of the doctors or main kitchen staff segregated waste despite having undergone training in healthcare waste management and segregation compared to nurses. This agrees with Pandit and Mehta (2005) study which found that nurses had significantly positive attitude when compared to the other hospital staff.

A section of the respondents observed that waste segregation was not taken seriously because no incident had occurred while others mentioned that it is a way of obtaining body tissues for witchcraft purposes. Such attitudes have been observed in a previous study by Manyele and Lyasenga (2010), indicating that the situation is similar in South Africa, Mozambique, Swaziland, Kenya and Tanzania. The findings point to the needed emphasis by EnviroNews (2005) that waste segregation will see all stakeholders in the health sector go a long way in reducing injuries in hospital. However, in terms of attitudes, nearly all of the respondents agreed, respectively that poor waste segregation can create health hazards in the community.

Further findings showed that while majority of the respondents have never felt discouraged with the practice, some of the respondents who have been discouraged lamented that after separating the waste; it was again put into inappropriate bags for disposal. Others complained of lack of disposal bags. Indeed, the results showed that over half of the respondents observed that the essential bags and containers were not enough. This agrees with Bontle et al., (2005) who noted that despite the magnitude of the problem, practices, capacities and policies in dealing with healthcare waste disposal has been inadequate. This is confirmed in the finding which showed that respondents in 
the study were unanimous that the hospital should have a waste segregation plan.

\section{Conclusions:}

Waste segregation is done across all the departments at the hospital except the accounts department. Syringes and needles make up most of the waste generated from the various departments at the hospital. Others were blood and body fluids, razor blades, chemicals and human tissue. These wastes are segregated by four colour codes: red, black, blue and yellow. Body fluids are mainly disposed in red bins; surgical blades and needles disposed in yellow (sharps) containers; human tissues disposed mainly in red bins and chemicals also disposed in red bins or the other bins. This latter practice is potentially dangerous because when mixed with nonhazardous waste, then all waste becomes hazardous.

Clear instructions and guidelines influence the practice of waste segregation among staff at the hospital. However, not all of the staffs were aware of these guidelines. Most of the staff had not undertaken any training on biomedical waste management. The few who had undertaken it were from radiology, pharmacy, laundry, housekeeping and nursing departments. These departments all practiced waste segregation more than the other staff from other departments. In addition, staffs were generally not aware of a document outlining the hospital waste management policy.

Staff at the hospital had a generally correct understanding of the concept of waste segregation. The quality of care and practice is reflected in all the areas of health care including waste segregation. The staff who have adequate knowledge practice waste segregation better than those who don't. Most of the staff are familiar with the colour codes used for segregation. Those without adequate knowledge do not practice segregation. Although some staff have not had any training since they joined the institution, a good number of them segregate waste. However, training was emphasized, along with provision of adequate waste bags.

Although staff generally had a positive attitude towards waste segregation, there were myths and misconceptions amongst some of the staff members in regards to the practice. Such misconceptions were: that all hospital waste is clinical waste thus there is no need for segregation. As a result, some staff members felt that it was an unnecessary waste of resources and time to segregate waste while others thought that it was not their responsibility.

Training on health care waste management should be done on regular basis. The right colour of bags should be provided in adequate quantity. It is also important to have a waste documentation system in order to know what percentage of waste is hazardous and what percentage is not. With the knowledge that only $15 \%$ of hospital waste is hazardous, a collection that is 
not corresponding with the expected amount will indicate poor segregation. This will help the hospital administration to assess the level of compliance. There are no policies and guidelines on waste segregation in the hospital. This should be introduced in order to guide and direct staff on what the institution expects of them. A waste segregation plan should be introduced.

This study was limited in scope to a single private tertiary hospital in Nairobi County, Kenya. Therefore, generalization of the study findings should be made with care. In order to validate the findings of this study therefore, a similar study could be conducted in another hospital of equal size. In addition, a study could be carried out in Kenya on the hospital with the best waste management practice for benchmarking purposes.

\section{References:}

1. Bontle, K.B., ( 2005). The Skills Portal-Exploring the new World of Work, Clean and Green Campaign: Johannesburg, South Africa.

2. Environews: (July 2005) International society of environmental Botanists Newsletter, 11(3), 5-7.

3. Manyele, S.V., Lyasenga, T. J., (2010). Factors affecting medical waste management in low level health facilities in Tanzania, African Journal of Environmental Science \& Technology, 4(5), 304-318.

4. Ministry of Health, Kenya (2007). National Standards and Guidelines on Injection safety and Medical Waste management, Nairobi.Kenya.

5. Ministry of Health, Kenya (2006). John Snow Injection safety in the context of infection prevention and control-participants handbook, Kenya. October Edition, 16-17.

6. Mokanyane, A. M., (2006). Feasibility of a healthcare waste Management strategy in Soshanguve. Pretoria, Gauteng, South Africa.

7. Pandit, N.B., Mehta, H.K., Kartha, G.P., Choudhary, S.K., (2005). Management of bio-medical waste: Awareness and practices in a district of Gujarat. Indian J Public Health, 1(49), 245-7.

8. Pruss, A., Giroult, E., \& Rushbrook, P., (1999). Safe management of Wastes from healthcare activities, Geneva: World Health Organization.

9. Rao, P.H., (2008). Hospital waste management-awareness and practices: A study of three states in India. Waste Manag Res, 1(26), 297-303.

10. Rasheed, S., Iqbal,S.,(2005). Hospital waste management in the teaching hospitals of Karachi. Sir Syed College of Medical Sciences, Karachi. India.

11. Rogers, H., (2005). Cities and Human Health: Waste, Water, Disease: The Waste Stream, from Gone Tomorrow: The Hidden Life of Garbage. New York: The New Press. 
12. Rolando,T.S., Loida, B.M., Danilo, G.M., (1997). Special Waste Fractions: Hospital Waste Management in the Philippines, Metro: Manila.

13. Saini, S., Nagarajan, S. S., \& Sarma, R. K. (2005). Knowledge, attitude and practices of bio-medical waste management amongst staff of a tertiary level hospital in India. J Acad Hosp Adm, 17(2).

14. Sandra, S., (2009). GTZ activities in the area of waste management in Asia-Routes for the Future: Bangladesh, India.

15. Singh, K., Arora, S.K., (2004). Bio-medical waste management in the U.T.,Chandigarh. Journal of Environmental Science and Engineering, 46(1), 55-60.

16. U.S. Environmental Protection Agency (2009). A User-Friendly Reference Document: Washington DC.

17. U.S. Environmental Protection Agency (2009). Guide for Infectious Waste Management, EPA/530-SW-86-014, Washington DC.

18. World Health Organization (1998). Characterization Of Municipal Solid Waste: Report No. Epa530-R-98-007: Franklin Associates, Ltd. Prairie Village, Kansas.

19. World Health Organization (2005). Decision making Guide, Management of Solid Health Waste at Primary Health Care Centres, Geneva, Switzerland.

20. World Health Organization (2006): World Alliance for Patient SafetyGlobal Patient Safety Challenge. Geneva. Switzerland

21. World Health Organization (October 2007). Health care waste management: Fact sheet No.1.

22. World Health Organization report, (2002). A focus for sanitation and disease management and education. Geneva, Switzerland 